\title{
Maternal Care and DNA Methylation of a Glutamic Acid Decarboxylase 1 Promoter in Rat Hippocampus
}

\author{
Tie-Yuan Zhang, ${ }^{1}$ Ian C. Hellstrom, ${ }^{1}$ Rosemary C. Bagot, ${ }^{1}$ Xianglan Wen, ${ }^{1}$ Josie Diorio, ${ }^{1}$ and Michael J. Meaney \\ ${ }^{1}$ Sackler Program for Epigenetics and Developmental Psychobiology at McGill University, Douglas Mental Health University Institute, McGill University, \\ Montreal, Quebec H4H 1R3, Canada, and 2Singapore Institute for Clinical Sciences, Singapore 117609
}

\begin{abstract}
Parenting and the early environment influence the risk for various psychopathologies. Studies in the rat suggest that variations in maternal care stably influence DNA methylation, gene expression, and neural function in the offspring. Maternal care affects neural development, including the GABAergic system, the function of which is linked to the pathophysiology of diseases including schizophrenia and depression. Postmortem studies of human schizophrenic brains have revealed decreased forebrain expression of glutamic acid decarboxylase 1 (GAD1) accompanied by increased methylation of a GAD1 promoter. We examined whether maternal care affects GAD1 promoter methylation in the hippocampus of adult male offspring of high and low pup licking/grooming (high-LG and low-LG) mothers. Compared with the offspring of low-LG mothers, those reared by high-LG dams showed enhanced hippocampal GAD1 mRNA expression, decreased cytosine methylation, and increased histone 3-lysine 9 acetylation (H3K9ac) of the GAD1 promoter. DNA methyltransferase 1 expression was significantly higher in the offspring of low- compared with high-LG mothers. Pup LG increases hippocampal serotonin (5-HT) and nerve growth factor-inducible factor A (NGFI-A) expression. Chromatin immunoprecipitation assays revealed enhanced NGFI-A association with and H3K9ac of the GAD1 promoter in the hippocampus of high-LG pups after a nursing bout. Treatment of hippocampal neuronal cultures with either 5-HT or an NGFI-A expression plasmid significantly increased GAD1 mRNA levels. The effect of 5-HT was blocked by a short interfering RNA targeting NGFI-A. These results suggest that maternal care influences the development of the GABA system by altering GAD1 promoter methylation levels through the maternally induced activation of NGFI-A and its association with the GAD1 promoter.
\end{abstract}

\section{Introduction}

Parenting influences endophenotypes that associate with a wide range of psychopathologies (Rapee, 1997; Carter et al., 2002). The challenge is that of establishing a direct relationship between parental care and the development of the neural systems that mediate the relevant cognitive and emotional endophenotypes, as well as identifying candidate mechanisms. One approach is that of examining maternal care in the rat, notably variations in pup licking/grooming (LG) (Liu et al., 1997; Francis et al., 1999; Weaver et al., 2004a,b). The adult offspring of mothers that naturally showing low levels of pup LG (i.e., low-LG mothers) show enhanced stress reactivity (Liu et al., 1997; Caldji et al., 1998; Francis et al., 1999; Weaver et al., 2004b; Toki et al., 2007), including increased dopamine stress responses in the medial prefrontal cortex (PFC) (Zhang et al., 2005). These animals also exhibit impaired sensorimotor gating as measured by prepulse inhibition (PPI) (Zhang et al., 2005). Impairments in PPI associate with an increased risk for psychopathology (Geyer et al., 1990,

Received Feb. 27, 2010; revised July 8, 2010; accepted July 31, 2010

This work was supported by a grant from the National Alliance for Research on Schizophrenia and Depression (T.-Y.Z.) and by funding from the Canadian Institutes for Health Research and the National Institute of Child Health and Development (M.J.M.).

Correspondence should be addressed to Dr. Tie-Yuan Zhang, Douglas Mental Health University Institute McGill University, 6875 LaSalle Boulevard, Montreal (Verdun), Quebec H4H 1R3, Canada. E-mail: tieyuan. zhang@douglas.mcgill.ca.

DOI:10.1523/JNEUROSCI.1039-10.2010

Copyright $\odot 2010$ the authors $\quad 0270-6474 / 10 / 3013130-08 \$ 15.00 / 0$
2001). Manipulations of rearing conditions influence the development of systems that mediate PPI (Ellenbroek et al., 1998; Ellenbroek and Cools, 2000, 2002).

The forebrain expression of glutamic acid decarboxylase (GAD), the rate-limiting enzyme in GABA synthesis, is decreased in schizophrenic patients (Akbarian et al., 1995; Guidotti et al., 2000b; Volk et al., 2000; Heckers et al., 2002). Such effects are a potential mechanism for the altered dopamine function that underlies psychosis (Benes, 1997). Studies with postmortem brain samples from schizophrenic patients reveal increased DNA methylation of the GAD1 promoter (Costa et al., 2006; Grayson et al., 2006; Kundakovic et al., 2007). DNA methylation associates with gene silencing and cortical GABAergic neurons from schizophrenic patients also show increased expression of DNA methyltransferase 1 (Ruzicka et al., 2007), which catalyzes cytosine methylation (Buryanov and Shevchuk, 2005; Goll and Bestor, 2005). Decreased GAD1 transcription is linked to increased DNMT1 association with the GAD1 promoter (Kundakovic et al., 2007). However, the developmental origins of such differences in the transcriptional regulation of GAD1 are unknown.

Maternal care alters hippocampal glucocorticoid receptor (GR) gene expression in the adult offspring through effects on DNA methylation of a neuron-specific, exon $1_{7}$ GR promoter. The maternal effect is mediated by enhanced serotonergic activity and increased expression of nerve growth factor-inducible factor A (NGFI-A) (Weaver et al., 2007). Thus, there is increased NGFI-A association with the exon $1_{7}$ promoter in pups of high- 
compared with low-LG mothers (Weaver et al., 2007). Serotonin (5-HT) induces demethylation of the exon $1_{7}$ promoter and increases GR expression in cultured hippocampal neurons: Both effects are blocked by an antisense targeting NGFI-A (Weaver et al., 2007), whereas an NGFI-A expression plasmid mimics the 5-HT effect (Weaver et al., 2007). Interestingly, the GAD1 promoter contains an NGFI-A consensus sequence (GenBank accession number AF110132.1), suggesting the intriguing possibility that the GAD1 promoter may be similarly regulated by maternal care. The studies reported here provide evidence for such a maternal effect on the epigenetic regulation of GAD1 expression that is comparable with that observed for the GR gene.

\section{Materials and Methods \\ Animals}

All procedures were performed in accordance with the guidelines established by the Canadian Council on Animal Care with protocols approved by the McGill University Animal Care Committee. The animals used were the male offspring of Long-Evans dams mated in our animal colony, which avoids confounds resulting from the stress of transportation. After mating, the females were housed singly on a standard $12 \mathrm{~h}$ light/ dark cycle (lights on at 8:00 A.M.) in polycarbonate maternity cages containing bedding, with ad libitum access to food and water. Cage cleaning began no earlier than postnatal day 10. Litters were left otherwise undisturbed with their respective dams until weaning on day 21 after which time the offspring from each litter were housed together in samesex groups of three to four per cage until postnatal day 45 (PND45). From PND45 onward, animals from each litter were housed in pairs until testing, which occurred at 3-4 months of age. One or two animals per litter were used for the study.

\section{Assessment of maternal behavior}

Maternal behavior was assessed using a procedure adapted from that previously described (Liu et al., 1997; Champagne et al., 2003). The frequency of maternal behaviors was scored on postpartum days 1 through 6. Observers were trained to a high level of interrater reliability $(>0.90)$. Dams were observed in their home cage and not disturbed for the duration of the $6 \mathrm{~d}$ observation period. Daily observations occurred during five, 75 min sessions, three of which were scheduled during the light phase (10:00 A.M., 1:00 P.M., and 5:00 P.M.) and two during the dark phase (7:00 A.M. and 8:00 P.M.) of the light cycle. Within each observation session, the behavior of each mother was scored 25 times (one observation/3 min) for pup LG (including both body and anogenital licking). Thus, each mother's LG frequency score was based on a total of 750 observations ( 25 observations/session $\times 5$ session $/ \mathrm{d} \times 6 \mathrm{~d}=750$ observations/mother) and was expressed as percentage occurrence (number of occurrences/750 $\times 100$ ).

Pups were designated as high- or low-LG on the basis of their mother's LG frequency score relative to the mean \pm 1 SD frequency score for the cohort ( $\sim 60-80$ mothers/cohort). High-LG mothers were defined as females whose LG frequency scores were $>1$ SD above the cohort mean. Low-LG mothers were defined as females whose LG frequency scores were $>1$ SD below the cohort mean.

\section{Quantitative real-time PCR}

Whole brains were rapidly removed and stored at $-80^{\circ} \mathrm{C}$. The hippocampal tissue was dissected and RNA extracted from one hemisphere using RNeasy mini kit (QIAGEN; catalog \#74106) with on-column DNase digestion (QIAGEN; catalog \#79254). The overall quality and yield of the RNA preparation was determined using SmartSpec plus spectrophotometer (Bio-Rad Laboratories). cDNA synthesis was completed using reverse transcriptase AMV (Roche Applied Science; catalog \#10109118001). Quantitative real-time PCR was performed with a LightCycler 480 (Roche Applied Science) and RT2 PCR primer set for rat GAD1 (Superarray Bioscience Corporation; catalog \#PPR06836A). $\beta 2$ Microglobulin $(\beta 2 \mathrm{M})$ (Superarray Bioscience Corporation; catalog \#PPR42607A) and GAPDH (glyceraldehyde-3-phosphate dehydrogenase) (Superarray Bioscience Corporation; catalog \#PPR06557A) refer- ence genes from same sample were amplified to control for potential loading errors. The results were identical with both controls and the results are expressed relative to $\beta 2 \mathrm{M}$.

\section{Chromatin immunoprecipitation assay}

Animals were perfused with $4 \%$ paraformaldehyde to cross-link proteinDNA complexes (Weaver et al., 2004b) and then stored at $-80^{\circ} \mathrm{C}$ until dissection. Hippocampi were dissected and chromatin was immunoprecipitated using rabbit polyclonal antibody to NGFI-A (Santa Cruz Biotechnology), acetylated histone H3-lysine 9 (Millipore; catalog \#07-352), or normal rabbit IgG nonimmune antibody (from Santa Cruz Biotechnology). One-tenth of the lysate was kept before immunoprecipitation and used to quantify DNA levels (input). The rat hippocampal GAD1 promoter region (GenBank accession number NM_017007.1; assay position, -399; chromosome ref sequence \#NC_005102.2; TSS position, 52789370) of the un-cross-linked DNA was subjected to quantitative PCR (qPCR) amplification [primer set; Superarray Bioscience Corporation; catalog \#GPR060837(-)01A].

\section{Sodium bisulfite mapping}

Cytosine methylation was determined using sodium bisulfite conversion followed by sequencing (Frommer et al., 1992; Clark et al., 1994). Hippocampal genomic DNA $(0.5 \mu \mathrm{g})$ was treated with sodium bisulfite (EpiTect Bisulfite kit; QIAGEN; catalog \#59104). The GAD1 promoter region (GenBank accession number AF110132) of bisulfite-treated DNA (0.5 $\mu \mathrm{g}$ ) was PCR amplified using outside primers (forward, 589-taa aaa gga aga gaa aga aga att att; reverse, 1074-tta aac tta act tta ctc tac cac aaa c). The PCR protocol included an initial denaturating cycle $\left(5 \mathrm{~min}, 95^{\circ} \mathrm{C}\right)$, followed by 34 cycles of denaturation $\left(1 \mathrm{~min}, 95^{\circ} \mathrm{C}\right)$, annealing $(2 \mathrm{~min}$ $\left.30 \mathrm{~s}, 55^{\circ} \mathrm{C}\right)$, and extension $\left(1 \mathrm{~min}, 72^{\circ} \mathrm{C}\right)$, followed by a final extension cycle $\left(7 \mathrm{~min}, 72^{\circ} \mathrm{C}\right)$ terminating at $4^{\circ} \mathrm{C}$. The PCR product was used as a template for subsequent PCR amplification using nested primers (forward, 828-ata ttt gta aag gag ttt tag gtt g; reverse, 1016-tcc tta ctt aca aaa tcc cta atc c). The nested PCR product was cleaned using QIAquick PCR purification kit (QIAGEN; catalog \#28104), subcloned (QIAGEN PCR cloning kit; catalog \#231124), and transformed to produce 20 different colonies per plate. Twenty plasmids per animal containing the ligated GAD1 promoter DNA fragment were sequenced at the Genome Québec Innovation Centre (McGill University, Montreal, Quebec, Canada).

\section{Hippocampal cell culture}

Hippocampi were dissected from embryonic day 20 embryos, trypsinized, homogenized, and seeded onto $60 \mathrm{~mm}$ plates at a density of $\sim 3 \times 10^{7}$ cells per plate. Media consisted of MEM $\alpha$ (Invitrogen) supplemented with $10 \% \mathrm{FBS}, 20 \mathrm{~mm} \mathrm{KCl}, 0.25 \%$ glucose, 15 mM HEPES, $0.1 \%$ penicillin/streptomycin, and $20 \mu \mathrm{M} 5^{\prime}$-fluorodeoxyuridine to prevent glial cell growth. Media was changed the following day and contained lentiviral vectors containing a short hairpin RNA (shRNA) directed against NGFI-A, an overexpression vector (OE) containing NGFI-A cDNA (Changelian et al., 1989), or the appropriate empty vector (EV) as control. In the overexpression experiments, the NGFI-A overexpression vector or empty vector were added the day after plating and the medium was changed every 3-4 d. In the shRNA experiments, cells were treated with a lentiviral vector containing NGFI-A shRNA or no insert (empty vector) the day after plating. After $3 \mathrm{~d}$ of lentiviral treatment, the medium was removed and replaced with either control media or media containing $1 \mu \mathrm{M}$ serotonin. Cells were harvested $9 \mathrm{~d}$ after plating in PBS and stored at $-80^{\circ} \mathrm{C}$. RNA was isolated using Roche HiPure RNA extraction kit. Reverse transcription reactions were then performed on $0.5 \mu \mathrm{g}$ of RNA using Roche AMV reverse transcriptase. cDNA thus generated was analyzed using quantitative real-time PCR (qRT-PCR). GAD67 protein level was measured by Western blot after $4 \mathrm{~d}$ of serotonin treatment ( $9 \mathrm{~d}$ after plating) in a separate experiment.

\section{Production of recombinant lentiviral vectors}

Plasmid construction. Viral vectors were derived from the human immunodeficiency virus-based lentiviral backbones generously supplied by collaborators (S. D. Andrews and M. Szyf, McGill University, Montreal, Quebec, Canada). For overexpression vector, NGFI-A cDNA (Changelian et al., 1989) was ligated into the pLenti6/V5-Topo vector plasmid 


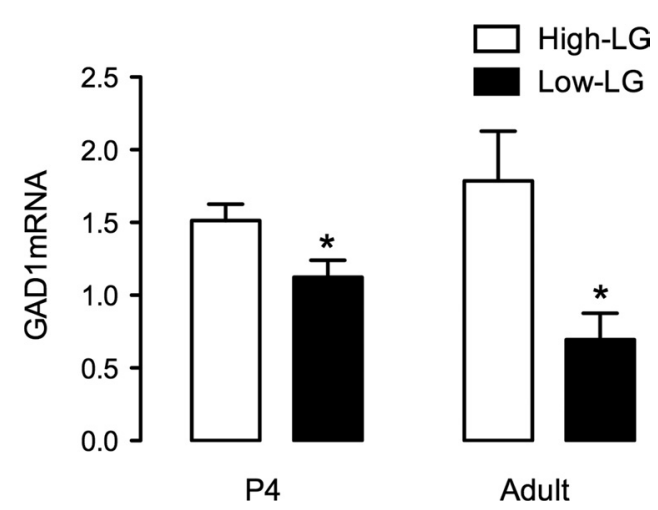

Figure 1. Influence of maternal care on hippocampal GAD1 expression. Mean \pm SEM levels of GAD1 mRNA quantified using qRT-PCR analysis of the amplified GAD1 mRNA (relative to the $\beta 2 \mathrm{M}$ standard) in the postnatal day 4 and adult offspring of high- or low-LG mothers ( $n=$ $4-8 /$ group; $^{*} p<0.05$ ).

(Invitrogen). The resulting expression plasmid contains a cytomegalovirus (CMV) promoter driving expression of NGFI-A or a random sequence (empty vector). For the short interfering RNA (siRNA)-containing vector, NGFI-A siRNA was acquired commercially (Open Biosystems) and subcloned into a pLVTHM plasmid (TronoLab) along with a GFP (green fluorescent protein) expression tag.

Preparation of virus. Virus was generated by transient cotransfection of the expression plasmid ( $15 \mu \mathrm{g}$ ), envelope plasmid (pMD2.G; TronoLab; $5 \mu \mathrm{g}$ ), and the packaging plasmids [for overexpression, $10 \mu \mathrm{g}$ of third generation packaging plasmids pRSVrev and pMDLg pRRE (TronoLab) were used; for siRNA, $10 \mu \mathrm{g}$ of second-generation packaging plasmid psPAX2 (TronoLab) ] into a $150 \mathrm{~mm}$ plate of $90 \%$ confluent HEK293T by calcium phosphate precipitation. Medium was collected 48 and $72 \mathrm{~h}$ after transfection, cleared of debris by low-speed centrifugation, and filtered through $0.45 \mu \mathrm{m}$ filters. High-titer stocks were prepared by an initial ultracentrifugation for $1 \mathrm{~h}$ at $138,000 \times \mathrm{g}$. Viral pellet was resuspended in sterile PBS and stored at $80^{\circ} \mathrm{C}$. After concentration typical titers ranged from $10^{7}-10^{8} \mathrm{TU} / \mathrm{ml}$. Sufficient virus was added to cultures to provide multiplicities of infection of 10 .

\section{Statistical analysis}

All statistical analyses were conducted using SPSS 15.0. Simple comparisons between two groups (high-LG and low-LG) were analyzed by independent Student's $t$ tests. For analyses involving factorial designs (maternal care and licking bout condition), the primary analysis conducted was a two-way ANOVA. Significant main effects and interactions were interpreted using Tukey's post hoc tests.

\section{Results}

\section{Hippocampal GAD1 expression}

We first examined differences in hippocampal GAD1 mRNA expression in the offspring of high- and low-LG mothers using qRT-PCR (with $\beta 2 \mathrm{M}$ as reference gene). There was a significantly $(t=2.82 ; \mathrm{df}=6 ; p=0.03)$ higher level of GAD1 mRNA in the adult offspring of high- compared with low-LG dams. This same maternal effect $(t=2.40 ; \mathrm{df}=14 ; p=0.03)$ was also apparent at postnatal day 4 (Fig. 1), suggesting dynamic regulation of GAD1 expression during early postnatal development.

\section{Maternal regulation of NGFI-A association with GAD1 promoter}

Maternal effects on hippocampal gene expression are associated with an increase in NGFI-A expression and NGFI-A association with relevant promoter sequences (Weaver et al., 2007). We used chromatin immunoprecipitation (ChIP) assays to examine NGFI-A association with the GAD1 promoter in postnatal day 4 pups as a function of concurrent mother-pup interaction. Hip-

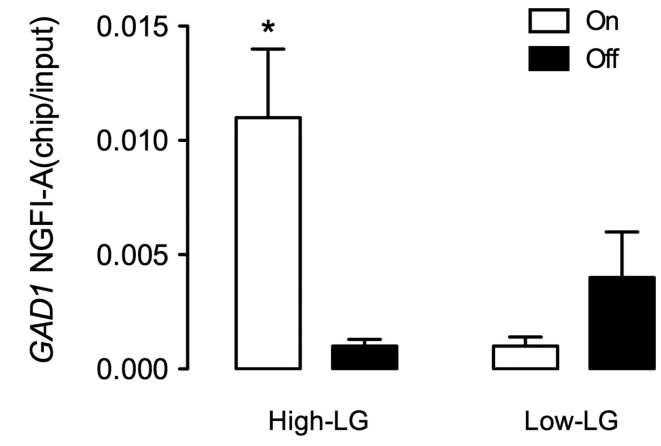

Figure 2. Maternal regulation of NGFI-A binding to the GAD1 promoter. Mean $\pm S E M q P C R$ data of the amplified GAD1 promoter sequence from NGFI-A immunoprecipitated hippocampal extract as a ratio of that from the input fraction. Hippocampal samples were obtained from the male, postnatal day 4 pups of high- or low- LG mothers immediately after a nursing bout (ON) or $25 \mathrm{~min}$ after the termination of a nursing bout (without any subsequent mother-pup interaction; 0FF; $n=4-6 /$ group; ${ }^{*} p<0.05$ from all other groups).

pocampal samples were obtained from pups immediately after periods of interaction (an "on" period) or a period in which the mother had been away from the litter for a minimum of $25 \mathrm{~min}$ without physical contact between mother and pup (i.e., an "off" period). An "on" bout was operationally defined as a period of observations in which the mother was in constant contact with the pups and recorded as being engaged in pup LG behavior. Note previous studies (Champagne et al., 2003, 2004) show that the differences in the pup LG between high- and low-LG mothers derive from a difference in the duration, but not the frequency of pup LG. In this study, the duration of an LG bout was $9.9 \pm 1.5$ min in the high-LG mothers and $3.1 \pm 0.7 \mathrm{~min}$ in low-LG mothers.

The results (Fig. 2) showed a significant interaction between the effects of maternal care and nursing bout condition $\left(F_{(1,14)}=\right.$ $13.62 ; p=0.002)$. Post hoc tests confirmed that the association of NGFI-A with the GAD1 promoter was significantly $(p<0.05)$ increased in pups of high- compared with low-LG mothers, but only after an "on" period ( $p=0.005)$. Samples obtained 25 min after no interaction between the mother and pup (i.e., the "off" period) showed no maternal effect on NGFI-A association with the GAD1 promoter (low-LG on vs low-LG off, $p=0.68$ ). These findings show an increase in NGFI-A association with the GAD1 promoter at the same period in life in which differences in GAD1 expression are apparent (Fig. 1).

\section{In vitro regulation of GAD1 expression}

The effects of maternal care on hippocampal gene expression are associated with an increase in 5-HT hippocampal turnover and increased NGFI-A expression (Mitchell et al., 1992; Meaney et al., 2000; Weaver et al., 2001, 2007). We found that 5-HT treatment of primary hippocampal neuronal cell cultures significantly increased $\mathrm{GAD}_{67}$ expression in hippocampal cultures (Fig. 3a,b) $(t=4.77 ; \mathrm{df}=7 ; p=0.002)$. Likewise, infection of primary hippocampal neuronal cultures with a lentivirus bearing an NGFI-A expression plasmid (Fig. 3c) was associated with a significant $\left(F_{(2,8)}=5.66 ; p=0.03\right)$ increase in GAD1 mRNA expression. Post hoc analysis showed that GAD1 mRNA levels were significantly $(p<0.01)$ higher than those in either the no-treatment or empty vector controls groups (Fig. $3 d$ ).

We then examined whether the effect of 5-HT on hippocampal GAD1 expression was mediated through NGFI-A. Hippocampal cultures were treated with 5-HT together with a lentiviral construct bearing a siRNA against NGFI-A mRNA or 
a

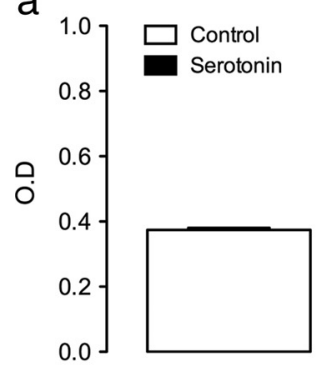

b
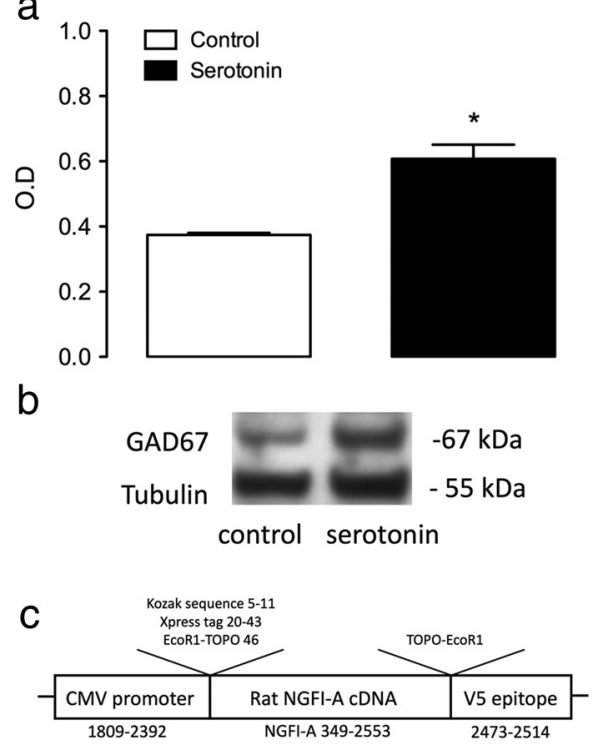

d
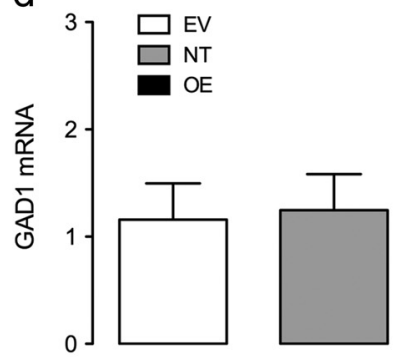

e

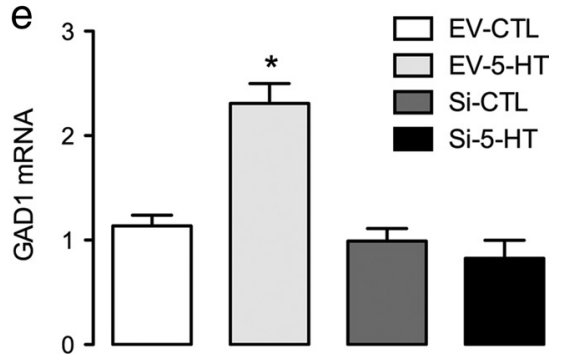

Figure 3. Regulation of GAD1 expression in primary hippocampal neuronal cell cultures. $\boldsymbol{a}$, Mean \pm SEM levels of $\mathrm{GAD}_{67}$ expression (relative optical density) quantified using Western blotting with samples from hippocampal cultures treated with serotonin (5-HT) $(1 \mu \mathrm{M})$ or medium alone $\left({ }^{*} p<0.01\right) \cdot \boldsymbol{b}$, Representative Western blots showing bands corresponding to $\mathrm{GAD}_{67}$ and $\alpha$-tubulin (used to control for loading variation). c, Physical map of the CMV/V5-His-NGFI-A expression vector. $\boldsymbol{d}$, Mean \pm SEM levels of GAD1 mRNA quantified using qRT-PCR analysis of the amplified GAD1 mRNA (relative to the $\beta 2 M$ standard) in primary hippocampal neuronal cultures treated with a lentiviral vector containing an NGFI-A expression plasmid (OE), the empty viral vector (EV), and a reference, no-treatment group (NT) $\left(n=8 /\right.$ group; $\left.{ }^{*} p<0.05\right)$. $\boldsymbol{e}$, Mean \pm SEM levels of GAD1 mRNA amplified from primary hippocampal neuronal cultures, quantified using qRT-PCR (with $\beta 2 \mathrm{M}$ as standard), treated with medium alone plus empty viral vector (EV-CTL), 5-HT in medium plus empty viral vector (EV-5-HT), medium alone plus the viral vector containing an NGFI-A siRNA (SI-CTL), and 5-HT in medium plus the viral vector containing an NGFI-A siRNA (SI-5-HT; $n=4-6 /$ group) in sample $\left({ }^{*} p<0.01\right.$ compared with all other groups).

an empty viral construct. There was a significant treatment effect $\left(F_{(1,22)}=8.18 ; p=0.01\right)$. Post hoc analysis revealed significantly $(p<0.05)$ lower GAD1 mRNA levels in cells cotreated with either 5-HT or media alone as well as with the NGFI-A siRNA compared with cells treated with 5-HT and the empty vector control. Among cultures treated with the empty vector, there was also a significant increase in GAD1 mRNA expression in 5-HTtreated compared with media alone (Fig. 3e). The results suggest that 5-HT treatment increases GAD1 expression and that this effect is mediated by NGFI-A.

\section{GAD1 promoter methylation}

Pup LG increases NGFI-A association with a GAD1 promoter. Increased NGFI-A binding in postnatal development is associated with alterations in chromatin structure and DNA methylation (Weaver et al., 2007). We used sodium bisulfite mapping in the region around the NGFI-A consensus sequence sites (Fig. 4a) to determine whether maternal care affects DNA methylation of the GAD1 promoter in adult hippocampus and prefrontal cortex. Since incomplete bisulfite conversion of cytosines will complicate sequence analysis, only sequences containing less than two unconverted sites in non-CpG positions were chosen for analysis. Our conversion efficiency in the current study was $99.8 \%$ in nonCpG sites, which compares favorably with that commonly reported in the literature (Kumaki et al., 2008).

Consistent with reports from other promoter regions (Bird, 1986), cytosine methylation levels were generally low across the $G A D 1$ promoter. However, there were significant differences in methylation levels in hippocampal samples from the adult offspring of high- and low-LG mothers (Fig. $4 b, c$ ). We compared the percentage of methylated clones in each group. Clones with one

or more methylated sites were counted as "methylated," and this value was divided by the total number of clones. The percentage of methylation in hippocampal samples was significantly higher in lowcompared with high-LG (Fig. $4 b$ ) (30.0 vs $8.7 \% ; t=-3.91, \mathrm{df}=8, p=0.004)$. We did not observe site-specific differences in methylation (Fig. 4c). However, CpG dinucleotides at sites 1-4 or sites 11-13 were among those sites most likely to show methylation, and the latter lie within the NGFI-A consensus sequence (Fig. 4a). Moreover, we did not find significant differences in methylation levels in the prefrontal cortex (mean percentage \pm SEM: high-LG, $13.4 \pm 4.0$, vs low-LG, $32.7 \pm 17.3 ; p=0.3$ ).

\section{Hippocampal DNMT1 expression}

DNMT1 plays an important role in the regulation and maintenance of DNA methylation, including the GAD1 promoter (Kundakovic et al., 2007, 2009). Thus, we examined differences in hippocampal DNMT1 mRNA expression in the offspring of high- and low-LG mothers using qRT-PCR (with $\beta 2 \mathrm{M}$ as reference gene). We found that DNMT1 expression was significantly higher in the offspring of low- compared with high-LG mothers (Fig. $5 a)(t=-2.50 ; \mathrm{df}=8 ; p=$ $0.04)$.

\section{Histone $\mathrm{H} 3$ lysine-9 acetylation of the GAD1 promoter}

DNA methylation is associated with alteration in chromatin states and transcription factor binding. Such effects can be mediated through effects on histone acetylation. The GAD1 promoter showed an approximately twofold and statistically significant $(t=2.45 ; \mathrm{df}=10 ; p=0.03)$ (Fig. $5 b, c)$ increase in H3-K9 acetylation in samples from the offspring of high- compared with low-LG mothers, as measured using ChIP with an antibody against acetylated H3-K9. H3-K9ac accompanies open chromatin states, increased transcription factor binding and active gene transcription. Thus, we then examined NGFI-A association with the GAD1 promoter in samples from the adult offspring of highand low-LG mothers using ChIP assays (Fig. 5b). There was significantly $(t=2.64 ; \mathrm{df}=7 ; p=0.03)$ increased levels of NGFI-A association with the $G A D 1$ promoter in the hippocampal samples from the adult offspring of high- compared with low-LG mothers. Note that we have previously shown that there are no differences in the levels of NGFI-A expression in the hippocampus of adult offspring of high- and low-LG mothers (Weaver et al., 2007). Thus, the differences in NGFI-A association with the GAD1 promoter occur despite comparable levels of NGFI-A protein and suggest an epigenetically regulated level of transcription factor binding.

\section{Discussion}

Previous studies reveal an effect of variations in maternal care on the development of corticolimbic GABAergic systems (Caldji et al., 1998, 2000, 2003; Fries et al., 2004). Cross-fostering studies show that such alterations are directly related to postnatal motherpup interactions (Caldji et al., 2003). The present study reveals a 
maternal effect on GAD1 expression in the hippocampus. This effect is tissue specific, with no comparable effect observed in the PFC.

Increased pup LG in the rat associates with enhanced binding of NGFI-A to the exon $1_{7}$ GR promoter and to alterations in CpG methylation (Weaver et al., 2004b, 2007). In adults, the decreased CpG methylation of the exon $1_{7}$ GR promoter increases H3-K9ac of and NGFI-A binding to the promoter, and increases GR expression. The differences in CpG methylation of the exon $1_{7}$ promoter are reversed with cross-fostering between high- and low-LG mothers shortly after birth (Weaver et al., $2004 b)$. The effect of pup LG is linked to an increase in hippocampal 5-HT turnover, and hippocampal cells treated with 5-HT show both a decrease in CpG methylation and an increase in GR expression; both effects are blocked with an siRNA directed against NGFI-A (Weaver et al., 2007). Likewise, NGFI-A overexpression leads to the demethylation of a methylated promoter construct. Site-directed mutagenesis within the NGFI-A response element of the construct eliminates NGFI-A binding and the effect on CpG methylation, suggesting that the binding of NGFI-A is essential for the effect on CpG methylation (Weaver et al., 2007).

Studies of maternal programming of GR expression suggest that the interaction between NGFI-A and its consensus sequence might alter DNA methylation; thus, our interest in whether other NGFI-A genomic targets might be subject to regulation by variations in maternal care.The results of the present experiments suggest a pattern of findings comparable with those reported with the GR gene. Increased pup LG enhanced NGFI-A association with the GAD1 promoter, and this effect was dependent on mother-pup interactions (Fig. 2). Likewise, 5-HT induced an increase in GAD1 expression that was blocked with a siRNA to NGFI-A. The effect of 5-HT on GAD1 expression in hippocampal neuronal cultures was mimicked by NGFI-A overexpression. This finding is consistent with that of a report showing that SDF1 $\alpha$-induced increases in GAD1 expression in cultured hippocampal neurons are mediated by an increased association of NGFI-A to the GAD1 promoter (Luo et al., 2008). These findings replicate previous results showing that maternally induced increases in NGFI-A expression are associated with an increase in NGFI-A association with NGFI-A-sensitive promoters, and stable epigenetic alterations (Weaver et al., 2004b, 2007). Indeed, Weaver et al. (2007) showed that an antisense oligonucleotide directed against NGFI-A could block the effects of 5-HT or cAMP on DNA methylation of the exon $1_{7}$ GR promoter.

The degree to which DNA methylation states vary in postmitotic cells has only recently been fully appreciated (Meaney and Szyf, 2005; Sweatt, 2009). This "epigenetic plasticity" is of profound importance for neurons, which are a highly stable, yet phenotypically dynamic cell population. The mechanism driving such alterations in CpG methylation has yet to be clearly explained; however, the present studies together with those of GR gene promoter suggest that increased transcription factor binding might promote the remodeling of DNA methylation. Stat3 binding to the gfap promoter is implicated in the alterations to

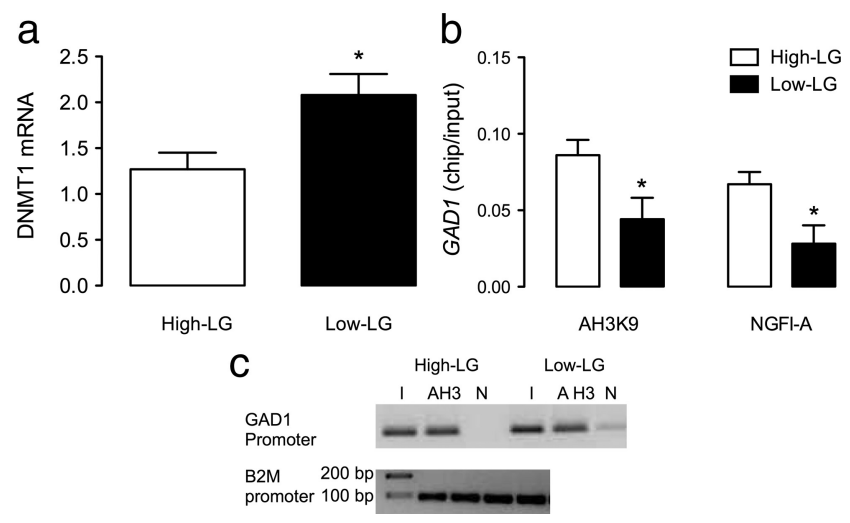

Figure 5. Maternal regulation of the epigenetic state of the GAD1 promoter. $\boldsymbol{a}$, Mean \pm SEM levels of DNMT1 mRNA quantified using qRT-PCR analysis of the amplified DNMT1 mRNA (relative to the $\beta 2 \mathrm{M}$ standard) in hippocampal samples derived from adult offspring of high- or low-LG mothers ( $n=5 /$ group; ${ }^{*} p<0.05$ ). $\boldsymbol{b}$, Mean \pm SEM qPCR data of the amplified GAD1 promoter sequence immunoprecipitated from hippocampal samples with an antibody to $\mathrm{H3}$ K9ac or NGFI-A and normalized to the input values ( ${ }^{*} p<0.05 ; n=4$ samples/group). c, Representative images of GAD1 and $\beta 2 \mathrm{M} q \mathrm{PCR}$ products on agarose gel confirming the amplification of a single specific product from chromatin immunoprecipitation assays described above.

CpG methylation that accompany the increased gfap expression during gliogenesis (Namihira et al., 2004; Fan et al., 2005). SP-1 binding, even in the absence of transcriptional activation, results in the remodeling of DNA methylation (Brandeis et al., 1994; MacLeod et al., 1994). Thus, environmental regulation of protein-DNA interactions appear to mediate epigenetic plasticity at the level of DNA methylation (Martinowich et al., 2003; Meaney and Szyf, 2005; Weaver et al., 2007).

The altered GAD1 expression in schizophrenia is associated with variations in DNA methylation (Costa et al., 2007). There is decreased GAD1 expression in cortical neurons of schizophrenic patients compared with controls (Veldic et al., 2005; Ruzicka et al., 2007) that is accompanied by increased DNMT1 expression (Veldic et al., 2004; Ruzicka et al., 2007) and increased CpG 
methylation (Costa et al., 2006; Mill et al., 2008). Such effects correspond to the decreased cortical GABAergic transmission and cognitive impairments in schizophrenia (Akbarian et al., 1995; Guidotti et al., 2000a; Lewis and Lieberman, 2000; Torrey et al., 2005). The downregulation of GAD1 mRNA is not associated with a change in the overall number of GABAergic neurons, suggesting an effect at the level of transcriptional regulation (Akbarian et al., 1995).

The adult offspring of low-LG mothers showed decreased hippocampal GAD1 expression, increased $\mathrm{CpG}$ methylation of the GAD1 promoter, and increased levels of DNMT1 mRNA. Grayson and colleagues (Kundakovic et al., 2007, 2009) provide evidence for a dynamic role of DNMT1 in the regulation of the DNA methylation state of the GAD1 promoter. DNMT1 inhibition upregulates GAD1 expression (Kundakovic et al., 2007) and decreases methylation of the GAD1 promoter (Kundakovic et al., 2009). Likewise, methionine treatment, which increases levels of the endogenous methyl donor $S$-adenosyl-methionine and thus CpG methylation, decreases GAD1 expression (Dong et al., 2005); this effect is blocked by a DNMT1 antisense (Noh et al., 2005). Interestingly, L-methionine treatment of schizophrenic patients worsens psychotic symptoms. These findings suggest a dynamic role for DNMT1 in the regulation of DNA methylation levels at selected genomic targets (Fan et al., 2005). DNMT1 acts in early development to maintain methylation patterns during cell replication. Interestingly, the adult expression of DNMT1 is pronounced in neurons, which are a stable cellular population at the level of replication, but remarkably dynamic at the level of function. These findings suggest that neuronal DNMT1 expression in adults is actively engaged in regulating methylation patterns. Moreover, DNMT1 expression in neurons is dynamically regulated by intracellular signaling pathways (Levenson et al., 2006). The same GABAergic neurons in the schizophrenic brain that express reelin and $\mathrm{GAD}_{67}$ exhibit an increase in DNMT1 (Veldic et al., 2004). Inhibition of DNMT1 in neuronal cell lines resulted in the increased expression of both reelin and $\mathrm{GAD}_{67}$ (Kundakovic et al., 2007).

The decreased hippocampal DNMT1 expression in the adult offspring of high-LG mothers was associated with decreased levels of DNA methylation across the GAD1 promoter and an increased level of $\mathrm{H3}-\mathrm{K} 9 \mathrm{ac}$ of and NGFI-A binding to the GAD1 promoter. The latter effect is observed despite the fact that the adult offspring of high- and low-LG mothers do not differ in constitutive levels of hippocampal NGFI-A expression (Weaver et al., 2007). H3-K9ac is a histone mark associated with open chromatin and increased transcription factor binding (Kadonaga, 1998; Roth et al., 2001). Increased cytosine methylation reduces levels of H3-K9ac and thus transcription factor binding through the recruitment of a repressor complex that commonly includes histone deacetylases (Klose and Bird, 2006). We suggest that the increased level of DNA methylation across the GAD1 promoter reduces NGFI-A binding and GAD1 transcription. In the case of hippocampal GR expression, chronic infusion of a histone deacetylase (HDAC) inhibitor into the adult offspring of low-LG mothers increases $\mathrm{H} 3$-K9ac of the exon $1_{7}$ GR promoter, NGFI-A association with its consensus sequence, and GR expression (Weaver et al., 2004b). The effects are accompanied by a decreased level of cytosine methylation of the exon $1_{7}$ promoter. HDAC inhibitors exert a comparable effect on GAD1 expression in vivo (Tremolizzo et al., 2002).

Overall levels of DNA methylation across the GAD1 promoter were generally low, raising the obvious question of whether such differences are indeed functionally relevant. The transcriptional silencing associated with methylation is mediated, in part, by the binding of methylated DNA binding proteins (MDBs) and the recruitment of repressor complexes (Klose et al., 2005; Klose and Bird, 2006). The binding of MDBs to DNA is remarkably sensitive requiring as few as one to two methylcytosines (Nan et al., 1993). These findings suggest that even low levels of methylation could potentially result in the recruitment of MDBs to the DNA site and alterations in transcriptional activity. Importantly, over three times as many $G A D$ promoter clones were methylated at least one CpG site in samples from adult offspring of low- compared with high-LG mothers (Fig. 4b).

These studies suggest that variations in maternal care can regulate the epigenetic state and expression of genes implicated in psychopathology, suggesting a specific developmental origin for the epigenetic modifications associated with mental health disorders (Mill et al., 2008). McGowan et al. (2009) provide evidence for a link between the quality of parent-child interactions and the methylation state and expression of the GR gene in human hippocampus. The findings presented here suggest that maternal care influences the development of the GABA system through epigenetic effects on selected genomic targets. The results are consistent with the idea that alterations in DNA methylation underlie the environmental regulation of genotype-phenotype relationships that influence neural function and mental health.

\section{References}

Akbarian S, Kim JJ, Potkin SG, Hagman JO, Tafazzoli A, Bunney WE Jr, Jones EG (1995) Gene expression for glutamic acid decarboxylase is reduced without loss of neurons in prefrontal cortex of schizophrenics. Arch Gen Psychiatry 52:258-266.

Benes FM (1997) The role of stress and dopamine-GABA interactions in the vulnerability for schizophrenia. J Psychiatr Res 31:257-275.

Bird AP (1986) CpG-rich islands and the function of DNA methylation. Nature 321:209-213.

Brandeis M, Frank D, Keshet I, Siegfried Z, Mendelsohn M, Nemes A, Temper V, Razin A, Cedar H (1994) Spl elements protect a CpG island from de novo methylation. Nature 371:435-438.

Buryanov YI, Shevchuk TV (2005) DNA methyltransferases and structuralfunctional specificity of eukaryotic DNA modification. Biochemistry (Mosc) 70:730-742.

Caldji C, Tannenbaum B, Sharma S, Francis D, Plotsky PM, Meaney MJ (1998) Maternal care during infancy regulates the development of neural systems mediating the expression of fearfulness in the rat. Proc Natl Acad Sci U S A 95:5335-5340.

Caldji C, Francis D, Sharma S, Plotsky PM, Meaney MJ (2000) The effects of early rearing environment on the development of $\mathrm{GABA}_{\mathrm{A}}$ and central benzodiazepine receptor levels and novelty-induced fearfulness in the rat. Neuropsychopharmacology 22:219-229.

Caldji C, Diorio J, Meaney MJ (2003) Variations in maternal care alter $\mathrm{GABA}_{\mathrm{A}}$ receptor subunit expression in brain regions associated with fear. Neuropsychopharmacology 28:1950-1959.

Carter JW, Schulsinger F, Parnas J, Cannon T, Mednick SA (2002) A multivariate prediction model of schizophrenia. Schizophr Bull 28:649-682.

Champagne FA, Francis DD, Mar A, Meaney MJ (2003) Variations in maternal care in the rat as a mediating influence for the effects of environment on development. Physiol Behav 79:359-371.

Champagne FA, Chretien P, Stevenson CW, Zhang TY, Gratton A, Meaney MJ (2004) Variations in nucleus accumbens dopamine associated with individual differences in maternal behavior in the rat. J Neurosci 24:41134123.

Changelian PS, Feng P, King TC, Milbrandt J (1989) Structure of the NGFI-A gene and detection of upstream sequences responsible for its transcriptional induction by nerve growth factor. Proc Natl Acad Sci U S A 86:377-381.

Clark SJ, Harrison J, Paul CL, Frommer M (1994) High sensitivity mapping of methylated cytosines. Nucleic Acids Res 22:2990-2997.

Costa E, Dong E, Grayson DR, Ruzicka WB, Simonini MV, Veldic M, 
Guidotti A (2006) Epigenetic targets in GABAergic neurons to treat schizophrenia. Adv Pharmacol 54:95-117.

Costa E, Dong E, Grayson DR, Guidotti A, Ruzicka W, Veldic M (2007) Reviewing the role of DNA (cytosine-5) methyltransferase overexpression in the cortical GABAergic dysfunction associated with psychosis vulnerability. Epigenetics 2:29-36.

Dong E, Agis-Balboa RC, Simonini MV, Grayson DR, Costa E, Guidotti A (2005) Reelin and glutamic acid decarboxylase 67 promoter remodeling in an epigenetic methionine-induced mouse model of schizophrenia. Proc Natl Acad Sci U S A 102:12578-12583.

Ellenbroek BA, Cools AR (2000) Animal models for the negative symptoms of schizophrenia. Behav Pharmacol 11:223-233.

Ellenbroek BA, Cools AR (2002) Early maternal deprivation and prepulse inhibition: the role of the postdeprivation environment. Pharmacol Biochem Behav 73:177-184.

Ellenbroek BA, van den Kroonenberg PT, Cools AR (1998) The effects of an early stressful life event on sensorimotor gating in adult rats. Schizophr Res 30:251-260.

Fan G, Martinowich K, Chin MH, He F, Fouse SD, Hutnick L, Hattori D, Ge W, Shen Y, Wu H, ten Hoeve J, Shuai K, Sun YE (2005) DNA methylation controls the timing of astrogliogenesis through regulation of JAKSTAT signaling. Development 132:3345-3356.

Francis DD, Champagne FA, Liu D, Meaney MJ (1999) Maternal care, gene expression, and the development of individual differences in stress reactivity. Ann N Y Acad Sci 896:66-84.

Fries E, Moragues N, Caldji C, Hellhammer DH, Meaney MJ (2004) Preliminary evidence of altered sensitivity to benzodiazepines as a function of maternal care in the rat. Ann N Y Acad Sci 1032:320-323.

Frommer M, McDonald LE, Millar DS, Collis CM, Watt F, Grigg GW, Molloy PL, Paul CL (1992) A genomic sequencing protocol that yields a positive display of 5-methylcytosine residues in individual DNA strands. Proc Natl Acad Sci U S A 89:1827-1831.

Geyer MA, Swerdlow NR, Mansbach RS, Braff DL (1990) Startle response models of sensorimotor gating and habituation deficits in schizophrenia. Brain Res Bull 25:485-498.

Geyer MA, Krebs-Thomson K, Braff DL, Swerdlow NR (2001) Pharmacological studies of prepulse inhibition models of sensorimotor gating deficits in schizophrenia: a decade in review. Psychopharmacology (Berl) 156:117-154.

Goll MG, Bestor TH (2005) Eukaryotic cytosine methyltransferases. Annu Rev Biochem 74:481-514.

Grayson DR, Chen Y, Costa E, Dong E, Guidotti A, Kundakovic M, Sharma RP (2006) The human reelin gene: transcription factors $(+)$, repressors $(-)$ and the methylation switch $(+/-)$ in schizophrenia. Pharmacol Ther 111:272-286.

Guidotti A, Pesold C, Costa E (2000a) New neurochemical markers for psychosis: a working hypothesis of their operation. Neurochem Res 25:1207-1218.

Guidotti A, Auta J, Davis JM, Di-Giorgi-Gerevini V, Dwivedi Y, Grayson DR, Impagnatiello F, Pandey G, Pesold C, Sharma R, Uzunov D, Costa E, DiGiorgi Gerevini V (2000b) Decrease in reelin and glutamic acid decarboxylase 67 (GAD67) expression in schizophrenia and bipolar disorder: a postmortem brain study. Arch Gen Psychiatry 57:1061-1069.

Heckers S, Stone D, Walsh J, Shick J, Koul P, Benes FM (2002) Differential hippocampal expression of glutamic acid decarboxylase 65 and 67 messenger RNA in bipolar disorder and schizophrenia. Arch Gen Psychiatry 59:521-529.

Kadonaga JT (1998) Eukaryotic transcription: an interlaced network of transcription factors and chromatin-modifying machines. Cell 92: 307-313.

Klose RJ, Bird AP (2006) Genomic DNA methylation: the mark and its mediators. Trends Biochem Sci 31:89-97.

Klose RJ, Sarraf SA, Schmiedeberg L, McDermott SM, Stancheva I, Bird AP (2005) DNA binding selectivity of MeCP2 due to a requirement for A/T sequences adjacent to methyl-CpG. Mol Cell 19:667-678.

Kumaki Y, Oda M, Okano M (2008) QUMA: quantification tool for methylation analysis. Nucleic Acids Res 36:W170-W175.

Kundakovic M, Chen Y, Costa E, Grayson DR (2007) DNA methyltransferase inhibitors coordinately induce expression of the human reelin and glutamic acid decarboxylase 67 genes. Mol Pharmacol 71:644-653.

Kundakovic M, Chen Y, Guidotti A, Grayson DR (2009) The reelin and
GAD67 promoters are activated by epigenetic drugs that facilitate the disruption of local repressor complexes. Mol Pharmacol 75:342-354.

Levenson JM, Roth TL, Lubin FD, Miller CA, Huang IC, Desai P, Malone LM, Sweatt JD (2006) Evidence that DNA (cytosine-5) methyltransferase regulates synaptic plasticity in the hippocampus. J Biol Chem 281:15763-15773.

Lewis DA, Lieberman JA (2000) Catching up on schizophrenia: natural history and neurobiology. Neuron 28:325-334.

Liu D, Diorio J, Tannenbaum B, Caldji C, Francis D, Freedman A, Sharma S, Pearson D, Plotsky PM, Meaney MJ (1997) Maternal care, hippocampal glucocorticoid receptors, and hypothalamic-pituitary-adrenal responses to stress. Science 277:1659-1662.

Luo Y, Lathia J, Mughal M, Mattson MP (2008) SDF1alpha/CXCR4 signaling, via ERKs and the transcription factor Egr1, induces expression of a 67-kDa form of glutamic acid decarboxylase in embryonic hippocampal neurons. J Biol Chem 283:24789-24800.

Macleod D, Charlton J, Mullins J, Bird AP (1994) Spl sites in the mouse aprt gene promoter are required to prevent methylation of the $\mathrm{CpG}$ island. Genes Dev 8:2282-2292.

Martinowich K, Hattori D, Wu H, Fouse S, He F, Hu Y, Fan G, Sun YE (2003) DNA methylation-related chromatin remodeling in activity-dependent BDNF gene regulation. Science 302:890-893.

McGowan PO, Sasaki A, D’Alessio AC, Dymov S, Labonté B, Szyf M, Turecki G, Meaney MJ (2009) Epigenetic regulation of the glucocorticoid receptor in human brain associates with childhood abuse. Nat Neurosci 12:342-348.

Meaney MJ, Szyf M (2005) Maternal effects as a model for environmentallydependent chromatin plasticity. Trends Neurosci 28:456-463.

Meaney MJ, Diorio J, Francis D, Weaver S, Yau J, Chapman K, Seckl JR (2000) Postnatal handling increases the expression of cAMP-inducible transcription factors in the rat hippocampus: the effects of thyroid hormones and serotonin. J Neurosci 20:3926-3935.

Mill J, Tang T, Kaminsky Z, Khare T, Yazdanpanah S, Bouchard L, Jia P, Assadzadeh A, Flanagan J, Schumacher A, Wang SC, Petronis A (2008) Epigenomic profiling reveals DNA-methylation changes associated with major psychosis. Am J Hum Genet 82:696-711.

Mitchell JB, Betito K, Rowe W, Boksa P, Meaney MJ (1992) Serotonergic regulation of type II corticosteroid receptor binding in hippocampal cell cultures: evidence for the importance of serotonin-induced changes in cAMP levels. Neuroscience 48:631-639.

Namihira M, Nakashima K, Taga T (2004) Developmental stage dependent regulation of DNA methylation and chromatin modification in a immature astrocyte specific gene promoter. FEBS Lett 572:184-188.

Nan X, Meehan RR, Bird A (1993) Dissection of the methyl-CpG binding domain from the chromosomal protein MeCP2. Nucleic Acids Res 21:4886-4892.

Noh JS, Sharma RP, Veldic M, Salvacion AA, Jia X, Chen Y, Costa E, Guidotti A, Grayson DR (2005) DNA methyltransferase 1 regulates reelin mRNA expression in mouse primary cortical cultures. Proc Natl Acad Sci U S A 102:1749-1754.

Rapee RM (1997) Potential role of childrearing practices in the development of anxiety and depression. Clin Psychol Rev 17:47-67.

Roth SY, Denu JM, Allis CD (2001) Histone acetyltransferases. Annu Rev Biochem 70:81-120.

Ruzicka WB, Zhubi A, Veldic M, Grayson DR, Costa E, Guidotti A (2007) Selective epigenetic alteration of layer I GABAergic neurons isolated from prefrontal cortex of schizophrenia patients using laser-assisted microdissection. Mol Psychiatry 12:385-397.

Sweatt JD (2009) Experience-dependent epigenetic modifications in the central nervous system. Biol Psychiatry 65:191-197.

Toki S, Morinobu S, Imanaka A, Yamamoto S, Yamawaki S, Honma K (2007) Importance of early lighting conditions in maternal care by dam as well as anxiety and memory later in life of offspring. Eur J Neurosci 25:815-829.

Torrey EF, Barci BM, Webster MJ, Bartko JJ, Meador-Woodruff JH, Knable MB (2005) Neurochemical markers for schizophrenia, bipolar disorder, and major depression in postmortem brains. Biol Psychiatry 57:252-260.

Tremolizzo L, Carboni G, Ruzicka WB, Mitchell CP, Sugaya I, Tueting P, Sharma R, Grayson DR, Costa E, Guidotti A (2002) An epigenetic mouse model for molecular and behavioral neuropathologies related to schizophrenia vulnerability. Proc Natl Acad Sci U S A 99:17095-17100. 
Veldic M, Caruncho HJ, Liu WS, Davis J, Satta R, Grayson DR, Guidotti A, Costa E (2004) DNA-methyltransferase 1 mRNA is selectively overexpressed in telencephalic GABAergic interneurons of schizophrenia brains. Proc Natl Acad Sci U S A 101:348-353.

Veldic M, Guidotti A, Maloku E, Davis JM, Costa E (2005) In psychosis, cortical interneurons overexpress DNA-methyltransferase 1. Proc Natl Acad Sci U S A 102:2152-2157.

Volk DW, Austin MC, Pierri JN, Sampson AR, Lewis DA (2000) Decreased glutamic acid decarboxylase 67 messenger RNA expression in a subset of prefrontal cortical gamma-aminobutyric acid neurons in subjects with schizophrenia. Arch Gen Psychiatry 57:237-245.

Weaver IC, La Plante P, Weaver S, Parent A, Sharma S, Diorio J, Chapman KE, Seckl JR, Szyf M, Meaney MJ (2001) Early environmental regulation of hippocampal glucocorticoid receptor gene expression: characterization of intracellular mediators and potential genomic target sites. Mol Cell Endocrinol 185:205-218.
Weaver IC, Diorio J, Seckl JR, Szyf M, Meaney MJ (2004a) Early environmental regulation of hippocampal glucocorticoid receptor gene expression: characterization of intracellular mediators and potential genomic target sites. Ann N Y Acad Sci 1024:182-212.

Weaver IC, Cervoni N, Champagne FA, D'Alessio AC, Sharma S, Seckl JR, Dymov S, Szyf M, Meaney MJ (2004b) Epigenetic programming by maternal behavior. Nat Neurosci 7:847-854.

Weaver IC, D'Alessio AC, Brown SE, Hellstrom IC, Dymov S, Sharma S, Szyf M, Meaney MJ (2007) The transcription factor nerve growth factor-inducible protein a mediates epigenetic programming: altering epigenetic marks by immediate-early genes. J Neurosci 27:17561768.

Zhang TY, Chrétien P, Meaney MJ, Gratton A (2005) Influence of naturally occurring variations in maternal care on prepulse inhibition of acoustic startle and the medial prefrontal cortical dopamine response to stress in adult rats. J Neurosci 25:1493-1502. 